\title{
Computer Camp \\ for the Handicapped and their Family Members
}

\author{
Vanja R. KISWARDAY, spec. pedagog \\ Department for applied mathematics, "Jožef Stefan" Institute, \\ Ljubljana, Slovenija
}

\begin{abstract}
With the rapid development of information technology and its increasing in all fields of life and work, there are practically no more workplaces without computer possibilities. In Slovenija everyone but the handicapped has a chance to join a computer class satisfying his interests. At the "Jožef Stefan" Institute, we made appropriate modifications to existing computer literacy programs to meet the special education needs of some children. We prepared a computer camp for handicapped children and their family members. The aim of this camp was to link the knowledge and first experience in computer use with their everyday needs. We found that it is important to introduce children's family members to various possibilities as to how the computer can become a useful tool in study, creative work and daily life. By inviting family members to join the camp, we encourage them to involve themselves in this process.
\end{abstract}

\section{Introduction}

The "Jožef Stefan" Institute is a research organization for pure and applied research in the natural sciences and technology. Both are closely interconnected in research departments composed of different task teams. Emphasis in basic research is given to the growth and education of young scientists, while applied research and development serve for the transfer of advanced knowledge, contributing to the development of the national economy and society in general.

The department of applied mathematics (OUM) has paid special attention to education: more than 40,000 participants have attended OUM education programs. In the field of youth education, OUM has 
organized various classes and work groups with regard to the different interests the students have in using the computer. In preparing of the programs we pay special attention to age, previous knowledge and the special interests of students.

\section{Experimental computer camp}

I started working at the Institute as a student of special pedagogy and gained some experience teaching children computer literacy. I realized that the computer has a significant motivation effect on children. They do not accept it as a complicated machine where you need a lot of knowledge and experience - as some adults do, - but as an interesting tool for creating, playing and studying. I saw their enthusiasm and good will to do anything with the computer. Time had no effect on their concentration at work, they were listening, working, enjoying and they did great jobs admired by adults.

In the publications "Computer and education" and "Educational computing", I read about the great results that special-needs children had with computer support. I saw that the computer can give those children more and new possibilities for study and creative work, opportunities in getting jobs and integrating into society.

I took up this challenge of introducing computers to children with special needs for my diploma work. With the help of the Institute special support of my mentor Bojan Rovtar, 86 children with special needs and some of their teachers we realized an experimental one-week computer camp for special school pupils. The results were very good. Children at the camp have been very interested in working with computers and they learned a lot. Their teachers noticed increased motivation in other activities like drawing, writing, communicating. We had many observations at this camp made by professors from the Faculty of Education, teachers from special-program school's, journalists, and we proved to them that computers are not only accessible for these children but can be, by a creative approach, also the key to their's activity. 


\section{Family computer camp}

After the first camp, we organised other camps organized for hearing and speech impaired, visually impaired and children with brain damage. All camps were highly successfull. Many parents showed interest in introducing themselves with programs and contents of the camp and occasions to include computers in their children's education and work. They showed interest in learning how to use computers themselves, too. Considering these requests, we prepared a FAMILY COMPUTER CAMP by including a "family members" program.

Work at camp was oriented around the project of publishing a camp review. There were four activities for young journalists: Writing for readers, Getting to know yourself, Excursions and Working with computers. For youth and adult's groups, we included contents related to the market economy and management. We divided participants into three groups based on their previous knowledge (some of children were in the camp for the third time), age and interests:

- Younger child group - pupils of elementary school,

- Youth group - mostly secondary school students,

- Adult group.

\section{Activities at the camp}

\subsection{Writing for readers.}

In this part, children got an insight into journalists work; they were visited by a well-known Slovenian journalist who told them about his work and showed them how to do an interview. Considering this information they prepare their own interview questions to get some answers about where people usually use computers. How can they write an interesting article - it seemed not to be a problem - at least not at camp, where their imagination is enormous. Anyway, they listen to some rules about the best way to transfer ideas on paper. 


\subsection{Getting to know yourself.}

This activity touched them with titles: My life story, Ways of getting know myself, The body, Feelings and my responses, My relationships, Masculinity and femininity, What should I do with the talents I possess?

Our intention was to invite young people to co-operate actively. First they examined their existing understanding of a given subject (photo-talk, poster drawing, discussion in pairs, etc.), then they tried to find its true significance (lectures) and evaluate it within our lives (life stories, stories, slides,...). All the notes and texts the young people worked with were compiled in his or her own "book".

\subsection{Excursions}

Our camp location was Zgornje Gorje near Bled. It is a small village under the Alps with many natural attractions and interesting tourist points. The beautiful surroundings inspired us with new ideas, and gave us an opportunity to lose all superfluous energy. One more important thing: we always met interesting people prepared to respond to our interview questions - in this way children integrated themselves in society and gained more self-confidence and courage in contacting other people.

\subsection{Market economy}

We animated the program for Youth and Adult's group with some contents from the area of market economy. They tried to earn some money on computer business simulations, then they made some calculations to find the best possibility to enrich that money by investing it in the bank, stock market or somewhere else. Those two groups also watched video films about successful managing in different situations, mistakes we usually make without noticing them and problems that appear as a consequence.

\subsection{Working with computers.}

It was a mix of learning how to use computers and, because of their enthusiasm, almost a real publishing office in the end.

In computer classes, we introduced them to: 
- computer (basic components, how to maintain computer),

- basic commands in DOS - how to load programs,

- simple program for desk publishing (News Master),

- word processor,

- spread sheets and databases,

- computer games for evening fun.

News Master is a simple program but very impressive and attractive for children. It has around 250 pictures and 34 different fonts. Almost all commands are present as icons and knowledge of English is not necessary. As a result, children learn how to work with this program almost immediately. For younger children this program was basic during this camp. They made a camp poster, a cover for a review, writings, riddles, cartoons, crosswords.

The next program they we introduced them to was a word processor. The youth group and adults used it to write all the reports, abstracts and other writings.

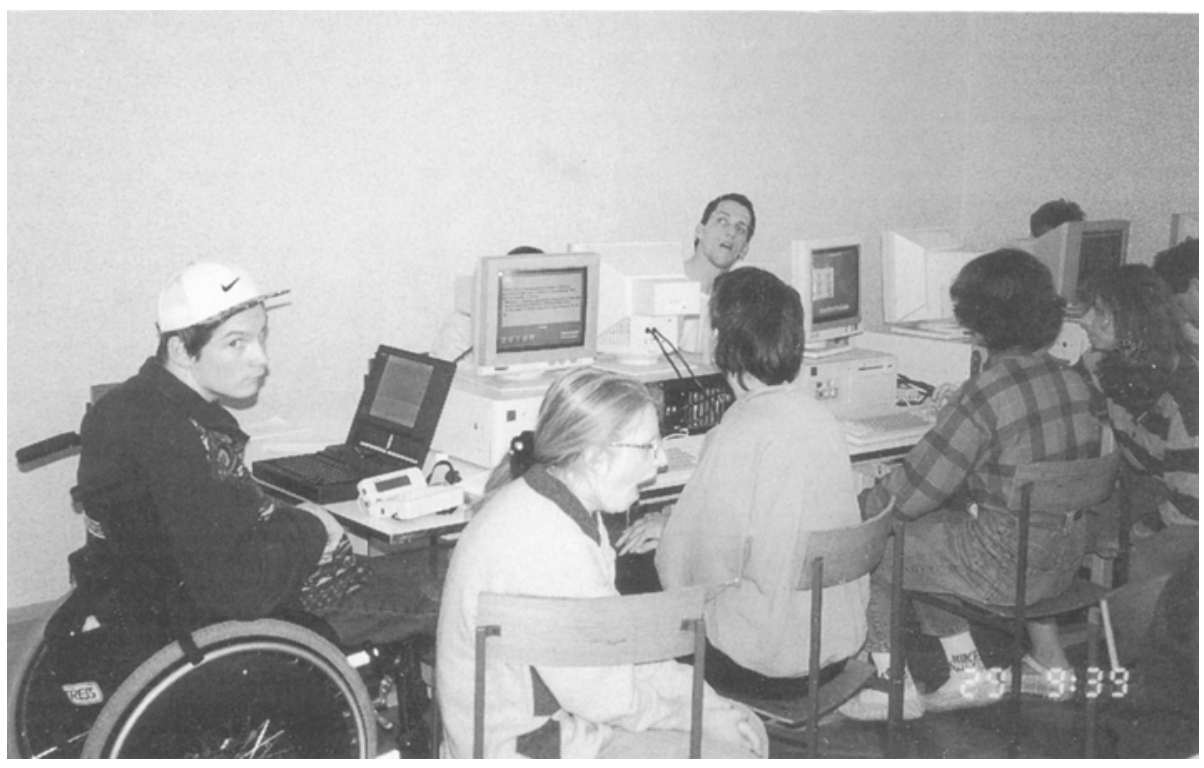

Fig. 1 Creating with computers 
We also learned about spreadsheets and how to prepare them to make a calculation of our assets. Younger children learned something about databases and made a directory with the names, addresses, telephone numbers and birth-days of all participants in the camp.

The last day we prepared a presentation of all we did during the week and we presented them a review published the last evening. We invited all family members and friends that could not participate in our camp. They were all most satisfied and shared the opinion that applying computers in their life can have a significant influence on their children's education and integration into society.

\section{Conclusion}

In this group of children the computer was not only a tool for writing, drawing, calculating and publishing the review. It also became a substitution for a skillful hand, communication aid, trigger for otherwise restrained abilities and a possibility to recognize the opportunity of equal integration in professional life that is now presenting itself as a future full of barriers and doubts for those young people.

These camps have an important role in the process of education and they give a unique opportunity for socialization and integration of children with special needs. For many of those children, this was their first experience of camp life; they gained more self confidence and confidence in friends and mentors. We were happy to hear from children's parents how grateful they were for this concrete way of helping them in educating their children for an independent life.

\section{References}

1. Goldenberg P. Computers, education and special needs, Addison Wesley publishing company, 1984

2. Heermann B. Teaching and learning with computers, Jossey-Bass Publishers, 1988

3. Kiswarday V., Rovtar B. Uvodni seminar za uporabo računalnika kot orodja Introductionary seminar: Using computer as a tool), "Jožef Stefan" Institute, Ljubljana 1991 